\title{
К ВОПРОСУ ОБ ОСОБЕННОСТЯХ ГРАММАТИКИ КИТАЙСКОГО ЯЗЫКА
}

\section{ON THE QUESTION OF CHINESE GRAMMAR FEATURES \\ N. Bogdanova \\ E. Solntceva}

Summary: In this article, the authors study the features of the Chinese grammar, which differs from the grammars of other languages by a few features. For example, if we talk about parts of speech, we should note that nouns in Chinese do not differ in gender, do not decline in cases, and do not change in numbers. In such cases, the Chinese language has special service words called counting words. The order of words in the language is strictly defined, if there is not the subject or some other part of the sentence, then such changes in the structure are always specified in the rules. The difference between the grammatical structure of the Russian and the Chinese languages is shown in illustrative examples. The research is based on the works of Chinese, Soviet and Russian linguists.

Keywords: Chinese, grammar, word order, parts of speech, China, morphology, inversion, word repetition, grammar history, predicates.
$\Pi$ ринято считать, что историю изучения грамматики в Китае можно разделить на два периода. Первый относится к временам, когда грамматика еще не являлась самостоятельной лингвистической дисциплиной. Древние китайские ученые были в основном сосредоточены на комментариях к памятникам старины, составляли словари, занимались классификацией иероглифов. По этой причине грамматические исследования проводились не слишком активно. Однако несмотря на то, что в древнем Китае языковеды не изучали грамматическую систему китайского языка с присущими ей закономерностями, тем не менее, уделяли особое внимание служебным словам с дальнейшими объяснениями их применения. [1]. Китайские филологи уже в XVIII в. разделили слова на знаменательные shízi 实字и служебные xйzi 虚字, а результаты трудов представили в исследованиях знаменательных и служебных слов, частей речи и предложений/фраз.

Второй период изучения грамматики китайского языка начался в конце XIX столетия и связан с появлением труда исследователя Ма Цзяньчжуна «Грамматический трактат Ма» в 1898 г. [2]. Эта работа получила широкую известность и значительно повлияла на дальнейшие исследования китайских языковедов. Существует мнение, что в силу типологических отличий китайского языка от

\author{
Богданова Надежда Андреевна \\ К.и.н., Российский университет дружбы народов \\ nad973@yandex.ru \\ Солнцева Елена Георгиевна \\ К.филол.н., Российский университет дружбы народов \\ solntseva-elena@yandex.ru
}

Аннотация: В данной статье авторы изучают особенности китайской грамматики, отличающейся от грамматик других языков рядом особенностей. Например, если говорить о частях речи, то стоит отметить, что существительные в китайском языке не различаются по родам, не склоняются по падежам, не изменяются по числам. В таких случаях в китайском языке существуют специальные служебные слова, называемые счетными. Порядок слов в языке строго определен, если в предложении пропущено подлежащее или какой-то другой член предложения, то такие изменения в структуре всегда оговорены в правилах. На наглядных примерах показано различие грамматического строя русского и китайского языков.

Материалом исследования послужили работы китайских, советских и российских лингвистов.

Ключевые слова: китайский язык, грамматика, порядок слов, части речи, Китай, морфология, инверсия, повтор слов, история грамматики, предикатов.

европейских, ученому пришлось «подгонять явления китайского языка под европейские схемы» [6. С.8].

Китайский язык отличается от русского и других европейских языков рядом грамматических особенностей: как в морфологии, так и в синтаксисе. Для него характерна строгая экономия грамматических средств, что проявляется в разных аспектах грамматического строя языка. Типология изолирующего строя предопределяет отсутствие в таких языках грамматических категорий, которые присутствуют в языках флективного строя. Многие китаисты утверждают, что грамматика просто-напросто отсутствует в китайской филологической традиции.

Известно, что в китайском языке часто бывает трудно отнести слово к какой-либо одной части речи, поскольку слова в большинстве случаев не имеют внешних морфологических признаков. Исследуя грамматику языков типа китайского, довольно часто возникает проблема определения принадлежности слов к той или иной части речи (в отличие от русского языка, в котором можно почти каждое слово отнести к определенной части речи).

Первая китайская грамматика исходила из того, что часть речи можно было выделить только в предложении, 
основываясь на семантическом критерии. Это обуславливает поиск в китайском строе аналогий грамматических категорий европейских языков не только со стороны китаистов, но и китайских лингвистов. В результате нормативная грамматика, используемая в учебниках для иностранцев (школьная грамматика в Китае отсутствует как таковая) не в состоянии адекватно объяснить условия употребления грамматических показателей скрытой системы, характеризующейся отсутствием морфологической согласовательной техники словоизменения и облигаторности. «Китайская грамота» по-прежнему остается тайной, известной лишь ее носителям.

Существительные китайского языка не различаются по родам, не изменяются по числам, не склоняются по падежам, но разделяются на исчисляемые и неисчисляемые. Однако, в отличие от европейских языков, в китайском языке существительные исчисляются с помощью специальных служебных слов, которые называются счетными. А.А. Драгунов в «Грамматике», опубликованной в 1952 г., сначала выделил 2 общие большие категории: имя и предикатив. Имя (существительное) у А.А. Драгунова противопоставлено предикативу (прилагательное и глагол, в китайском языке часто выступающие в роли сказуемого). Глагол и прилагательное в современном языке обозначают действие, качество, признаки действия, как протекает действие. Чтобы употребить имя существительное как сказуемое, необходима связка. Единственным морфологическим показателем числа в китайском языке служит суффикс - men \{1] (обязателен для местоимений множественного числа), который употребляется с существительными, обозначающими лица, а также при обращении:

一 он 他、 они 他们

一я 我、мы我们

- ученики 学生们, также можно сказать без суффрикca 学生

一 学生们, 你们早上好 ! Доброе утро, студенты!

Здесь стоит отметить факультативность употребления суффикса в случае присутствия других показателей множественности:

- многие друзья: 许多朋友 или можно сказать 许多 朋友们

Суффикс можно не ставить, если множественное число передается при помощи числительных и счетных слов, например:

- 十个工人 десять рабочих

一 三位教授mpu npopeccopa

В случае если существительное соединяется с указательным местоимением при помощи слова «некоторые, несколько» хіё 些, суффикс теп 们 предпочтительнее не использовать:

这些工程师 эти инженеры
Интересен случай употребления суффикса men 们 в сочетаниях имя +имя, когда men 们, обозначая множественность всех, приписывается одному слову, как правило, последнему:

\section{老师学生们 учителя и студенты}

В работе В.А. Курдюмова «Курс китайского языка. Теоретическая грамматика» автор приводит еще один случай употребления men 们, для перехода предмета от неодушевленного состояния к одушевленному с целью достичь «эффекта персонификации» [6. С. 210].

Глаголам китайского языка не свойственно изменение по числам и родам, спряжение по лицам. А.А. Драгунов, признавая аморфную природу исследуемого им языка [5. С. 44], отмечал, что глагольная морфема, взятая сама по себе, «не содержит никаких указаний на время, ни на залог, ни на вид и не имеет финитного характера. Вот почему глагол в китайском языке должен быть соответствующим образом оформлен, чтобы функционировать как финитное сказуемое в законченном предложении» [5. С. 127]. Для подтверждения своего тезиса А.А. Драгунов приводит перечень формальных показателей, например, отрицание bù 不 «не», или же наречие уе̌ 也 «тоже» и т.д. С другой стороны, если отсутствует морфологическое оформление глагольного сказуемого, это тоже является своего рода показателем какого-либо значения. Тань Аошуан в тезисах докладов [8. С. 103-110] отмечает, что «в случае отсутствия такого оформления предложение перестает передавать данное значение» [8. С. 108]. Неоформленный глагол передает, как правило, действие, относящееся к настоящему или будущему времени.

Прилагательное в китайском языке, как и существительное, не изменяется по родам, числам и падежам, а значение степеней сравнения выражаются в языке лексически:

\section{她很漂亮 Она красивая}

这几个姑娘很漂亮 Эти девушки красивые

你更漂亮 Ты еше красивее

他没有你漂亮 Он не такой красивый, как ты

По своим грамматическим свойствам прилагательное ближе к глаголу (в отличие от русского языка, в котором прилагательные вместе с существительными образуют одну общую категорию имени). Отечественными лингвистами, начиная с А.А. Драгунова, принято объединять глагол и прилагательное в одну категорию или группу на основе таких критериев, как возможность употребления без глагола - связки shi 是, в том числе в предложениях с отрицанием bù 不:

一 他学习中文 Он учит китайский язык 他不学习中 文 (了) Он не будет учить китайский язык(сказуемое глагол)

一 这幅画儿漂亮 Эта картина красивая 这幅画儿不 
漂亮 Эта картина некрасивая (сказуемое прилагательное)

С точки зрения построения предложения китайского языка, рамки достаточно четко определены. Принято считать, что обычное предложение в китайском языке должно иметь подлежащее и сказуемое.

一 我们都学习мы все учимся

Если это предложение-сообщение, а сказуемое в нем переходный глагол, то последний должен иметь дополнение:

\section{一 我每天早上做早操 я каждое утро делаю зарядку}

Если же предложение имеет характер суждения, после связки в нем должна находиться именная часть сказуемого. В таких предложениях предикативные отношения между существительным и существительным (что-то есть что-то, или некто является кем-то) необходимо оформлять связкой shi 是, например:

一 我是学生 $9 \mathrm{cmyденm}$

一 他是医生 Он доктор

一这个公园里到处都是红叶、黄叶 В этом парке повсюду красные и желтые листья.

Следует отметить, что в устной речи допускаются конструкции без употребления глагола-связки shi 是, например, в предложениях:

一 我莫斯科人 Я москвич

- 今天星期三 Сегодня среда

Однако, при наличии отрицания использование связки необходимо:

一 我不是莫斯科人 $Я$ не москвич

- 今天不是星期三 Сегодня не среда

Недопустимо говорить:

一 我不莫斯科人 $Я$ не москвич

- 今天不星期三 Сегодня не среда

Тем не менее, правилом оговаривается, что с наречиями уе̌ 也、 dōu 都постановка shì 是 не обязательна:

一 我朋友今年也十八岁 Моему другу в этом году тоже 18 лет

一我朋友今年也是十八岁 Моему другу в этом году тоже 18 лет

一 汉语班的学生都十九岁 Всем студентам группы китайского языка 19 лет

一 汉语班的学生都是十九岁Всем студентам группы китайского языка 19 лет

Ни подлежащее, ни сказуемое не должны содержать лишних повторяющихся слов. Подлежащее, как правило, предшествует сказуемому, сказуемое-сообщение следует за подлежащим и предшествует дополнению. Таким образом, случаи, не удовлетворяющие этим условиям, можно считать нарушением нормальной структуры предложения. Такими нарушениями являются пропуск слов, повтор и инверсия.

Пропуск слов обычно присутствует в предложении в случае продолжения речи. К продолжению речи следует отнести фразы, продолжающие либо сказанное другим лицом (например, ответ, возражение и т.п.), либо сказанное ранее тем же самым человеком.

Например, в диалоге:

我问玛丽: “玛丽，王忠是哪国人?" Я спросил Мэри: «Мэри, откуда родом Ван Чжун?»

玛丽回答说 :"是中国人。“Мэри ответила: «Из Китая»

(Перед словами是中国人 “из Китая” пропущено подлежащее Ван Чжун, здесь следует говорить о продолжении чужой речи.)

Помимо пропуска подлежащего в предложении китайского языка также возможен пропуск дополнения, пропуск слова в позиции обстоятельства, именной части сказуемого, сказуемого.

Следует отметить, что кроме пропуска слов при продолжении речи, возможны пропуски слов «сохраняющиеся по традиции» [3. С. 190], например, местоимений 我я，你 mы, которые могут быть пропущены не только в случае продолжения речи. Также возможно опустить в предложении такие слова как год, число 岁, 日 (или в устной речи 号). Так, вместо фразы "八月二十四且 двадиать четвертое число августа" допускается употребление фразы без "日 ri" "八月二十四 двадиать четвертое августа".

Или, например, фразу"我今年三十一岁 Мне в этом году тридиать один год" можно заменить на “我今年三 +- Мне в этом году исполнилось тридиать один". В первом случае - продолжение чужой речи, во втором - продолжение собственной речи. В таких случаях допускается пропуск некоторых слов, присутствующих в составе предыдущего предложения. Может быть пропущено подлежащее, дополнение, слова в позиции обстоятельства и т.д.

\footnotetext{
你去看电影吗? - ( 我) 去 Tы nойдешь в кино? - (Я) ПойӘy
}

При повторе следует различать повтор значения (само слово не повторяется дважды, а заменяется словом-заместителем) и повтор слова. В «Грамматике» Ван Ляо - И выделяет два типа повторов: повтор слов, имеющих грамматическое значение и стилистическое значение.

Например, в современном китайском языке в некоторых грамматических правилах следует повторять глагол 
при наличии двух дополнений при глаголе, например, прямого дополнения и дополнения длительности:

我看书看了一个小时。Ячитал книгучас.

(Здесь имеет место грамматическое значение в случае повтора глагола.)

Если же фраза звучит как 他做的是他做的(Что он делает, это он делает), то здесь значение повтора уже стилистическое. В таких случаях повтор слова нужен для привлечения внимания собеседника к сказанному.

В случае инверсии важно различать инверсию обязательную и инверсию свободную [3. С. 198]. При обязательной инверсии просто невозможно обойтись без изменения порядка слов в предложении, в специальных конструкциях, когда вынос дополнения является обязательным. Например, в предложениях 她兵兵球打得很好 в настольный теннис она играет очень хорошо, или 连 一杯茶也没有喝，就走了 Әаже чашки чая не выпил, сразу ушел.

Наиболее распространенный порядок слов: подлежащее - сказуемое - дополнение. Наречие в китайском языке предшествует слову, которое оно характеризует (обычно глаголу или прилагательному). Порядок слов в предложении китайского языка можно сравнить с мозаикой, где каждый элемент занимает свою строго определенную позицию. Например, определение в предложениях китайского языка занимает фиксированное место до определяемого слова. Независимо от степени распространенности и сложности структуры оно всегда предшествует определяемому слову, при этом оформляется суффиксом 的 de, который как раз и показывает наличие определения перед ним.

Поэтому довольно большую сложность составляет перевод с китайского цепочек определений, которые предшествуют определяемому существительному.

Таким образом, возможно, что утверждение некоторых языковедов об отсутствии грамматики в китайском языке, не совсем соответствует реальной ситуации. Изучая грамматику такого языка как китайский, следует принять как данное отсутствие грамматических категорий, некоторые особенности постановки членов предложения, например, позиция определения, обстоятельства места, которое фиксируется строго перед сказуемым и после подлежащего. Если по-русски фразу 我在中学学 习英语 «я учу английский язык в школе» можно сказать "я в школе учу английский язык», а также «в школе я учу английский язык», то по - китайски порядок в данном случае неизменен, т.к. позиция обстоятельства места «в школе» непосредственно после подлежащего и перед сказуемым, поэтому если перевести предложение дословно с китайского языка, то получаем фразу «я в школе учу английский язык». Изучив определенные правила о постановке служебных слов, членах предложения, об изменении в некоторых случаях порядка слов и другие особенности грамматики китайского языка, усвоение настолько далекого и необычного иностранного языка может оказаться довольно-таки успешным.

\section{ЛИТЕРАТУРА}

1. 高名凯。语法理论。北京。1960年。20页「ао Минкай «Теория грамматики». Пекин. 1960 г. 20 с.

2. 马建忠。马氏文通。上海。1924年Ма Цзяньчжун «Грамматический трактат Ма». Шанхай. 1924.

3. Ван Ляо - И. Основы китайской грамматики. Перевод с кит. Г.Н. Райской. М. 1954. 261 с.

4. Горелов В.И. Теоретическая грамматика китайского языка». М. 1989. 318 с.

5. Драгунов А.А. Исследования по грамматике современного китайского языка. М., 1952. 232 с.

6. Курдюмов В.А. Курс китайского языка. Теоретическая грамматика. М. 2005.576 с.

7. Семенас А.Л. Лексика китайского языка. М.:АСТ: Восток - Запад , 2005. 310 с.

8. Тань Аошуан. Финитность как проблема метаязыка флективного строя и семантические классы глагольных предикатов // 3 Международная конференция: «Языки Дальнего Востока, Юго-Восточной Азии и Западной Африки». Тезисы докладов. С. 107 - 110, М.1995 